\title{
BMJ Open Accidents and injuries related to powered paragliding: a cross-sectional study
}

Francesco Feletti, ${ }^{1,2}$ Jeff Goin ${ }^{3,4}$

To cite: Feletti F, Goin J. Accidents and injuries related to powered paragliding: a cross-sectional study. BMJ Open 2014;4:e005508. doi:10.1136/bmjopen-2014005508

- Prepublication history for this paper is available online. To view these files please visit the journal online (http://dx.doi.org/10.1136/ bmjopen-2014-005508)

Received 17 April 2014 Revised 2 August 2014 Accepted 6 August 2014

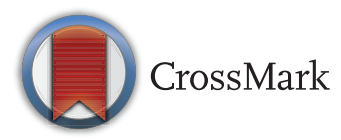

${ }^{1}$ U.O. Radiologia, Ospedale S. Maria delle Croci-Presidio Ospedaliero di Ravenna, Ausl della Romagna, Ravenna, Italy ExtremeSportMed, Bologna, Italy

${ }^{3}$ B.S. Aeronautical Science, Embry Riddle Aeronautical University, Daytona Beach, Florida, USA

${ }^{4}$ U.S. Powered Paragliding Association, Dover, Delaware, USA

Correspondence to Dr Francesco Feletti; feletti@extremesportmed.org

\section{ABSTRACT}

Objectives: Powered paragliding (PPG) and paragliding are two totally different sports, mainly because of the use of an engine in powered paragliding. As a consequence, the pattern of injuries caused by each of these two sports may be different.

Setting: To test this hypothesis, we analysed 384 incident reports gathered by the US Powered Paragliding Association from 1995 to 2012. The majority of the incidents occurred in the USA, while 26 incidents occurred elsewhere: Canada (8), Mexico (5), Panama (1), China (1), Japan (1), Malaysia (1), Indonesia (Java) (1), Europe (8): of which Spain (1), Belgium (1), UK (3), Italy (1), Romania (1), unknown (1).

Outcome: To identify the most affected body area and the most common type of injury sustained in PPG, and to highlight any differences from paragliding.

Results: The most affected body areas in PPG were the upper limbs $(44.5 \%)$, followed by the lower limbs $(32 \%)$, the back $(9.8 \%)$, the head $(7 \%)$, the pelvis (3.1), the chest $(2.7 \%)$ and the abdomen $(0.7 \%)$ $(p<0.001)$. The engine caused 43 accidents $(11.2 \%)$ in our study and was responsible for the majority of injuries to the upper limbs. The number of fatal accidents in PPG is not lower than in paragliding and hang-gliding.

Conclusions: To help prevent the specific injuries of PPG, the most appropriate equipment should be identified. The results of this study also suggest that, in the future, this sport should be analysed separately from paragliding.

\section{INTRODUCTION}

Powered paragliding (PPG) or paramotoring is a sport in which the pilot flies by means of a wing similar to that of paragliding, the sport from which it is derived, under which the crew is suspended by means of long lines. It is a sport in its own right-different because the equipment used includes an engine, worn on the back and held in place by a harness (figure 1 ).

In contrast with paragliding, which is practised over hilly or mountainous areas because

\section{Strengths and limitations of this study}

- This is the first study in the literature on powered paragliding.

- We analysed a large amount of data (384 incident reports) collected from 1995 to 2012.

- Under-reporting bias, due to the voluntary nature of data submission, cannot really be estimated, because there is no way to find out the exact number of people who were aware of the existence of the database.

- Data analysis was performed by only one researcher with no cross-checking.

it requires a descent in order to take off, a paramotor can take off from level ground thanks to the power of the engine. It is safer to fly over level ground because there are fewer obstacles, the thermals are not too strong, and winds are generally steady. Furthermore, PPG differs from paragliding because the thrust of the engine allows the paramotor pilot to take off and fly without the need for strong winds or thermals, therefore in safer and more stable weather conditions. However, compared with other aerial sports, paragliding remains the most similar to PPG: they both require the pilot to keep the wing inflated by means of his/her own weight and skill.

PPG was invented in the 1980s and rapidly gained popularity-so much so that various national and international competitions have been held throughout the world over the last few years. In 2007, it was estimated that, in the USA alone, the sport was practised by 3000 people. ${ }^{1}$ It seems to be a prevalently male sport; in 2013, the number of female members of the US Powered Paragliding Association represented only $2.6 \%$ of the total membership.

As PPG has grown in popularity, the number of accidents associated with it has inevitably increased. Knowledge of the accident dynamics, the type of injuries sustained 
Figure 1 Paramotor in flight.

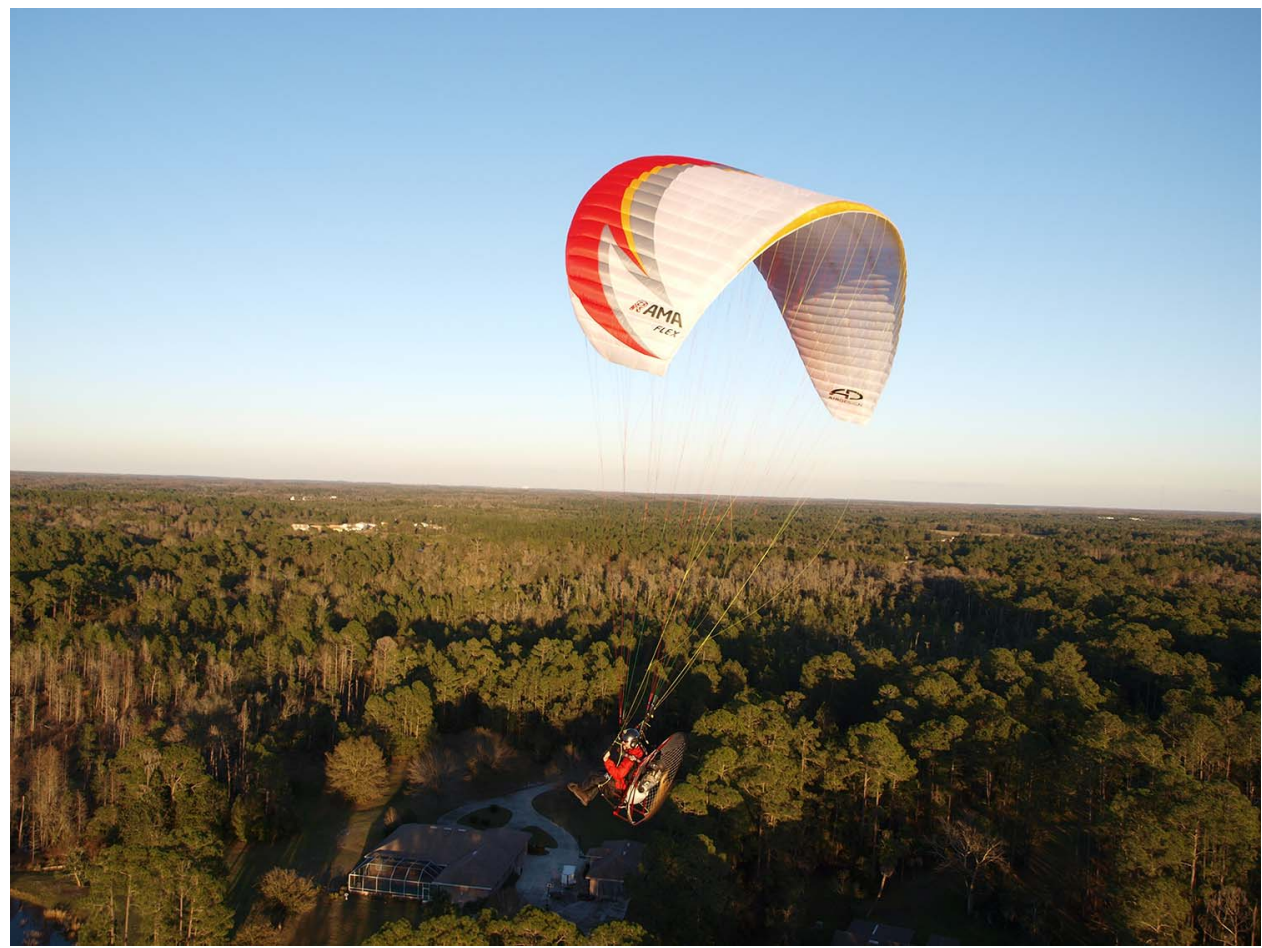

and the body area affected is of vital importance in sports medicine, in order to provide insight into the types of conduct, protective clothing and safety systems that should be adopted to improve safety.

A careful examination of the literature led us to conclude that there are no existing studies on this sport in the medical literature, except for a case we had previously reported $^{2}$; in a recent literature review, ${ }^{3}$ this sport is only mentioned among the varieties of paragliding, with which it is usually grouped.

Given that flying a paramotor is very different from flying a paraglider, we expected that the accident and injury types would differ greatly between the two sports as a result. The aim of this study was therefore to clarify the dynamics of paramotoring accidents, the conditions in which these occur, and the type of injuries sustained, and to highlight any differences from paragliding.

\section{MATERIALS AND METHODS}

We analysed incident reports of accidents that occurred between 1995 and the end of 2012, which the US Powered Paragliding Association (USPPA) had collected using a specific form published on its website. ${ }^{4}$ Data collection started in 1995; we decided to use all the data available between 1995 and 2012 (the starting date of the present study). Data were primarily collected for accidents in the USA but, as USPPA is popular among powered paragliders worldwide, accidents in other countries were also reported.

The forms submitted had been completed by the pilot involved, a witness, or the Association itself based on the information gathered. The form included drop-down menu lists, checklists and text fields. It consisted of five sections:

1. General information (date, time and place of the accident)

2. Pilot information: including demographic information and details of the pilot's PPG experience

3. Details on the accident: including a description of the type of accident, the main cause, weather conditions at the time, characteristics of the takeoff and landing area, and details of the pilot's clothing and equipment

4. Injury information: including the body parts affected, the seriousness of the injury, any medical assistance and possible collateral damage to people or things

5. Narrative: an extensive description of the event and its consequences

The form lacked a specific question about the nature of the injuries, but careful reading of the narrative section allowed us to obtain this information from almost all the forms. When these data were missing, they were designated 'unknown' in the results. The narrative section was read by only one researcher.

The data published by the USPPA were public and anonymous; their use for study and publication purposes was authorised beforehand by the USPPA. The data were analysed using descriptive statistics, using the software Wizard Pro 1.3.27 and the $\chi^{2}$ test.

The following definition of injury was adopted: 'any physical complaint sustained by an athlete that results from training or competition, irrespective of the need for medical attention or time lost from sports activities'. ${ }^{5-7}$ Each incident report was also given a National Advisory Committee of Aeronautics (NACA) score: a 
7-point system ${ }^{8}$ developed to assess the severity of injuries and diseases sustained or developed during aviation accidents. However, it was not possible to distinguish between classes V and VI in all cases on the basis of the available data. These two classes both cover conditions that pose an immediate threat to life and require immediate emergency medical assistance; therefore we decided to consider them as a single category.

We subsequently focused on accidents resulting in injury (disregarding those with a NACA score of 0 ), and we divided these into three classes based on the severity of the injuries:

1. minor (NACA I, II), usually not requiring emergency medical measures

2. major (NACA III, IV, V, VI), almost always requiring emergency medical measures

3. fatal (NACA VII)

We associated the accidents thus classified with the accident dynamics cited in the incident reports and with the phase of flight in which the accidents occurred. We also explored the correlation between injury severity and pilot rating, and between injury severity and accident dynamics.

\section{RESULTS}

At the start of the study, 384 incident reports were available. One had been submitted twice, therefore one copy was retained and the other was excluded.

The pilots involved in PPG accidents were aged between 24 and 72 years (average age 44.5, median 48, SD 9.54).

The majority of the accidents described occurred in the USA, while 26 occurred elsewhere: Canada (8), Mexico (5), Panama (1), China (1), Japan (1), Malaysia (1), Indonesia (Java) (1), Europe (8): of which Spain (1), Belgium (1), UK (3), Italy (1), Romania (1), unknown (1). Only three accidents involved a female pilot. Pilot injuries were classified according to the NACA category (table 1 ).

The following factors were taken into consideration: the phase of flight during which the accident took place (table 2), the primary cause (table 3 ) and the type of accident (table 4).

The rating for the experience of the pilots involved was as follows: $25.5 \%$ PPG2 (pilots who have an experience of 40 or more flights ${ }^{4}$ ), 13.5\% PPG1 (experience of 2 flights or more), 15.1\% PPG3 (experience of 200 or more flights), $9.1 \%$ instructor, $12.8 \%$ none, $11.7 \%$ not applicable, $6 \%$ unknown, $1.8 \%$ other. No statistically significant correlation was found in our sample between accident severity and pilot rating $\left(\chi^{2}, \mathrm{p}=0.044\right)$.

Data for the type of place where the accidents occurred were as follows: $70.5 \%$ flat terrain, $11.4 \%$ not applicable, $8.8 \%$ hilly terrain, $2.6 \%$ water, $2.6 \%$ mountainous terrain, $2.6 \%$ unknown data, $1.3 \%$ other.

To identify the most affected body areas and therefore obtain the data most critical for the development of

\begin{tabular}{|c|c|c|c|}
\hline Category & Description & Pilots & $\begin{array}{l}\text { Per } \\
\text { cent }\end{array}$ \\
\hline NACA 0 & No injury or disease & 194 & 50.6 \\
\hline NACA I & $\begin{array}{l}\text { Slight injury or illness. No } \\
\text { acute medical intervention } \\
\text { necessary }\end{array}$ & 59 & 15.4 \\
\hline NACA II & $\begin{array}{l}\text { Slight to moderately severe } \\
\text { injury or illness. Further } \\
\text { diagnostic examination } \\
\text { needed or outpatient medical } \\
\text { investigation, but usually no } \\
\text { emergency medical measures } \\
\text { necessary }\end{array}$ & 48 & 12.5 \\
\hline NACA III & $\begin{array}{l}\text { Moderate to severe but not } \\
\text { life-threatening disorder. } \\
\text { Emergency medical measures } \\
\text { usually on the site }\end{array}$ & 43 & 11.2 \\
\hline NACA IV & $\begin{array}{l}\text { Severe injury or illness where } \\
\text { rapid development into a } \\
\text { life-threatening condition } \\
\text { cannot be excluded. } \\
\text { Emergency medical care is } \\
\text { required }\end{array}$ & 11 & 2.9 \\
\hline NACA V & $\begin{array}{l}\text { Acute vital (life-threatening) } \\
\text { danger }\end{array}$ & 5 & 1.3 \\
\hline NACA VI & $\begin{array}{l}\text { Breathing and/or cycle } \\
\text { stopped and/or resuscitation }\end{array}$ & & \\
\hline NACA VII & Death & 23 & 6 \\
\hline
\end{tabular}

protective clothing, we calculated the number of injuries sustained in each body area (table 5). Of a total of 256 injuries, the most affected body areas were the upper limbs $(44.5 \%)$, followed by the lower limbs $(32 \%)$ and back $(9.7 \%)$.

Of the 23 fatal accidents, five were the result of unintentional landing on water and drowning; one autopsy revealed the cause of death to be drowning, which was probably the consequence of unconsciousness due to the head injury sustained. Another two accidents were fatal because of cerebral spine fractures with spinal cord damage. In four cases, death was caused by severe head trauma. In all remaining cases, death was the result of high-energy multitrauma, although the reports do not allow us to identify precisely the injury responsible for death.

Table 2 Phase of flight

\begin{tabular}{lrl}
\hline Phase of flight & Count & Per cent \\
\hline Takeoff (including inflation and run up) & 165 & 43 \\
Cruise & 107 & 27.9 \\
Landing (including approach and after & 55 & 14.3 \\
landing) & 56 & 14.6 \\
\hline Not available/other & & \\
\hline
\end{tabular}




\section{Table 3 Primary causes of accidents}

\begin{tabular}{lrl}
\hline Primary cause & Total & $\begin{array}{l}\text { Per } \\
\text { cent }\end{array}$ \\
\hline Pilot errors (only) & 205 & 53.5 \\
Mechanical failure (including fuel & 67 & 17.5 \\
exhaustion) & & \\
Pilot error and weather & 17 & 4.4 \\
Pilot error and mechanical failure & 17 & 4.4 \\
Weather (gust, thermal, rain, wind & 22 & 5.7 \\
increase, etc) & & \\
Not applicable/unknown & 24 & 4.4 \\
Other & 31 & 1.8
\end{tabular}

*Including takeoff disturbed by wake turbulence created by the passage of other aircraft and landing out of the landing zone (LZ).

Most injuries were minor (NACA I-II), followed by major ones (NACA III-VI) and fatal ones (NACA VII). No significant difference was found in the distribution of fatal, major and minor injuries among the three main phases of flight (takeoff including inflation and run up, cruise, and landing including approach).

With regard to the relationship between accident dynamic and accident severity, accidents due to body contact with a spinning prop and wing malfunction/ deflation prevalently caused major injuries (NACA IIIVI): $55.6 \%$ and $56.2 \%$, respectively. Accidents due to water immersion were prevalently fatal $(71.4 \%)$. The other dynamics of injury were mainly associated with minor injuries (NACA I-II). A statistical correlation between injury severity and type of accident was found $\left(\chi^{2}, \mathrm{p}<0.021 ; 95 \%\right.$ confidence); severity of injury by type of accident is shown in table 6 .

The correlation between accident severity and pilot rating is barely significant $\left(\chi^{2}, \quad \mathrm{p}=0.044 ; 95 \%\right.$ confidence).

The data on collateral damage from the various accidents reveal that, in addition to the 383 pilots directly involved, 7 bystanders and 16 pilots of other aircrafts involved in collisions were also injured, making a total of

Table 4 Types of accidents

\begin{tabular}{lll}
\hline Type & Total & Per cent \\
\hline Collision with terrain/obstruction on & 76 & 19.8 \\
ground & & \\
Power plant equipment malfunction & 58 & 15.1 \\
Body contact with spinning prop & 43 & 11.2 \\
Hard landing & 40 & 10.4 \\
Fall & 37 & 9.7 \\
Wing malfunction or deflation & 35 & 9.1 \\
Other & 29 & 7.5 \\
Handling & 20 & 5.2 \\
Line tangle/damage & 15 & 3.9 \\
Collision with other aircraft/ultralight & 14 & 3.6 \\
Water immersion & 10 & 2.6 \\
Other/not applicable & 35 & 1.5 \\
\hline
\end{tabular}

406 people. The data are insufficient to classify the severity of the injuries suffered by these people precisely. No injuries were sustained in 13 cases.

\section{DISCUSSION}

In our study, the weather conditions were a main or contributing cause of $10.1 \%$ of the accidents: weather conditions alone were the cause of $5.7 \%$ of the accidents, while the weather conditions contributed to the accident together with pilot error in $4.4 \%$ of the accidents. This figure is much lower than that reported for paragliding by Zeller et $a l,{ }^{9}$ who mentions adverse weather conditions as a cause in $19 \%$ of paragliding accidents. This can be explained by the fact that an engine allows frequent flying and in a much wider variety of weather conditions, so pilots are less likely to risk flying in extreme and hazardous conditions.

However, our study clearly shows that the use of an engine influences the accident dynamics. It can itself be the cause of accidents, it can be an important aggravating factor in the event of an accident, or it can be the direct cause of injury.

This study shows that takeoff is the most dangerous phase of flight in PPG $(32.9 \%$ of the accidents took place during this phase of flight; or $43 \%$ if we include those during run up and inflation, phases that can be considered an integral part of takeoff with a paramotor), whereas, in paragliding, the most dangerous phase is landing. ${ }^{3}$ This can be explained by the fact that takeoff with a PPG requires a delicate balance between the thrust of the engine, the weight of the crew and the lift of the wing. In addition, takeoff from level ground and the prevalently horizontal thrust of the engine results in the pilot moving away from the ground slowly, in contrast with paragliding, where the distance from the ground increases rapidly because takeoff is from a slope. As a result, the falling distance remains decreased for much longer during takeoff with a PPG than it does in paragliding, limiting the possibility of adopting emergency manoeuvres and making the use of an emergency parachute impossible.

The use of an engine can be the direct cause of accidents typical of PPG: the two causes listed as 'fuel exhaustion' and 'mechanical failure: power plant/propeller' were responsible for $14 \%$ of accidents.

The engine may also aggravate the accident, mainly because of the energy it produces and transmits to the crew, but also because of its weight. It is mounted on a special frame worn by the pilot: the overall weight of the equipment and accompanying power plant vary between 20 and $40 \mathrm{~kg}$. In the case of a collision, these two factors synergise to make the impact more traumatic given that engine displacement varies between $80 \mathrm{cc}$ and $250 \mathrm{cc}$ and engine power varies between 11 and $22.5 \mathrm{~kW}$; engine thrust is at its highest during takeoff, the phase of flight when PPG accidents most frequently occur. In some reports, it is explicitly mentioned that it was 
Table 5 Distribution of injuries sustained in different body regions in powered paragliding found in this study $\left(\chi^{2}, p<0.001\right)$

\begin{tabular}{|c|c|c|c|c|c|}
\hline $\begin{array}{l}\text { Body } \\
\text { region }\end{array}$ & $\begin{array}{l}\text { Body } \\
\text { area }\end{array}$ & Cases & Type of injury (number of cases) & Total & $\begin{array}{l}\text { Percentage of all } \\
\text { injuries }\end{array}$ \\
\hline \multirow[t]{3}{*}{ Head } & Head & 7 & Concussion (3), unknown (2), contusion (1), open wound (1) & 18 & 7 \\
\hline & Neck & 3 & Burn (1), C2 fracture (1), unknown (1) & & \\
\hline & Face & 8 & Fracture (4>), laceration (2), burn (1), other (1) & & \\
\hline Chest & Chest & 7 & $\begin{array}{l}\text { Rib fracture (2), abrasion (1), burn (1), contusion (1), open } \\
\text { wound (1), unknown (1) }\end{array}$ & 7 & 2.7 \\
\hline \multirow[t]{6}{*}{ Upper limb } & Shoulder & 32 & $\begin{array}{l}\text { Fracture (6), open wound (5), bruising (4), other (3), } \\
\text { tendon injury (3), dislocation ( } 2 \text {, laceration (2), unknown (2), } \\
\text { abrasion (1), burn (1), contusion (1), muscle strain (1), } \\
\text { sprain (1) }\end{array}$ & 114 & 44.5 \\
\hline & Arm & 26 & $\begin{array}{l}\text { Laceration (7), burn (5), contusion (3), fracture (3), unknown } \\
\text { (3), open wound (2), tendon rupture (1), abrasion (1), sprain (1) }\end{array}$ & & \\
\hline & Forearm & 11 & $\begin{array}{l}\text { Burn (2), laceration (2), fracture (2), unknown } \\
\text { (2), contusion (1) open wound (1), soft tissue injury (1) }\end{array}$ & & \\
\hline & Wrist & 8 & Fracture (3), contusion (2), laceration (1), other (1), sprain (1) & & \\
\hline & Elbow & 5 & Open wound (2), abrasion (1), burn (1), unknown (1) & & \\
\hline & Hand & 32 & $\begin{array}{l}\text { Fracture (17; } 11 \text { with amputation), open wound (6), laceration } \\
\text { (3), contusion (2), muscle strain (1), other (1), sprain (1), } \\
\text { unknown (1) }\end{array}$ & & \\
\hline Abdomen & Abdomen & 2 & Contusion (1), soft tissue injury (1) & 2 & 0.7 \\
\hline Back & Back & 25 & $\begin{array}{l}\text { Fracture (8), unknown (8), other (3), contusion (2), abrasion (1), } \\
\text { burn (1), muscle strain (1), open wound (1) }\end{array}$ & 25 & 9.7 \\
\hline Pelvis & Pelvis & 8 & $\begin{array}{l}\text { Fracture (4), contusion (1), internal bruising (1), muscle strain } \\
\text { (1), other (1) }\end{array}$ & 8 & 3.1 \\
\hline \multirow[t]{5}{*}{ Lower limb } & Thigh & 13 & $\begin{array}{l}\text { Fracture (4), contusion (2), laceration (2), open wound (2), } \\
\text { abrasion (1), burn (1), unknown (1) }\end{array}$ & 82 & 32 \\
\hline & Knee & 19 & $\begin{array}{l}\text { Contusion (4), sprain (4), laceration (2), ligament rupture (2), } \\
\text { unknown (2), abrasion (1), dislocation (1), meniscus and } \\
\text { ligament tear (1), muscle strain (1), other (1) }\end{array}$ & & \\
\hline & Calf & 17 & $\begin{array}{l}\text { Fracture (7), burn (2), contusion (2), laceration (2), } \\
\text { unknown (2), wound (2) }\end{array}$ & & \\
\hline & Ankle & 22 & $\begin{array}{l}\text { Sprain (8), fracture (5), contusion (3), unknown (3), } \\
\text { dislocation (1), ligament rupture (1), other (1) }\end{array}$ & & \\
\hline & Foot & 11 & $\begin{array}{l}\text { Fracture (3), unknown (3), contusion (2), other (2), } \\
\text { laceration (1) }\end{array}$ & & \\
\hline
\end{tabular}

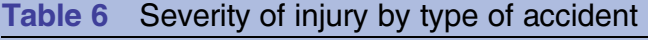

\begin{tabular}{llll}
\hline Type of accident & $\begin{array}{l}\text { Minor } \\
(\%)\end{array}$ & $\begin{array}{l}\text { Major } \\
(\%)\end{array}$ & $\begin{array}{l}\text { Fatal } \\
(\%)\end{array}$ \\
\hline $\begin{array}{l}\text { Collision with terrain/ } \\
\text { obstruction on ground }\end{array}$ & 62.5 & 18.8 & 18.8 \\
$\begin{array}{l}\text { Power plant equipment } \\
\text { malfunction }\end{array}$ & 100 & 0 & 0 \\
$\begin{array}{l}\text { Body contact with spinning } \\
\text { prop }\end{array}$ & 44.4 & 55.6 & 0 \\
$\begin{array}{l}\text { Hard landing } \\
\text { Fall }\end{array}$ & 74.1 & 22.2 & 3.7 \\
$\begin{array}{l}\text { Wing malfunction or } \\
\text { deflation }\end{array}$ & 54.5 & 40.9 & 4.5 \\
$\begin{array}{l}\text { Other } \\
\text { Handling }\end{array}$ & 31.2 & 56.2 & 12.5 \\
Line tangle/damage & 80 & 0 & 20 \\
$\begin{array}{l}\text { Collision with other aircraft/ } \\
\text { ultralight }\end{array}$ & 100 & 0 & 0 \\
$\begin{array}{l}\text { Water immersion } \\
\text { All types of accident }\end{array}$ & 14.3 & 40 & 20 \\
\hline & 56.6 & 31.2 & 12.3 \\
\hline
\end{tabular}

precisely the energy supplied by the engine that made the impact fatal.

Some reports state that pilot error had been to some extent caused by a state of mental confusion suffered by the pilot during the execution of acrobatic stunts. Steep spirals are extremely dangerous manoeuvres in PPG; the position of the crew and the centrifugal acceleration (increased by the thrust of the engine) may reduce blood supply to the brain, which could cause a momentary state of mental confusion or even blackouts at a time when the maximum level of attention is required. ${ }^{10}$

In the case of immersion in water, the weight of the engine can rapidly drag the pilot under the surface, giving him/her no time to free himself/herself from the equipment, making this type of accident particularly feared among paramotor pilots. In our study, this dynamic was responsible for $21.7 \%$ of fatal accidents (71.4\% of accidents involving water immersion were fatal) and a serious (non-fatal) case of near-drowning. It is therefore inadvisable to fly a paramotor over or near 


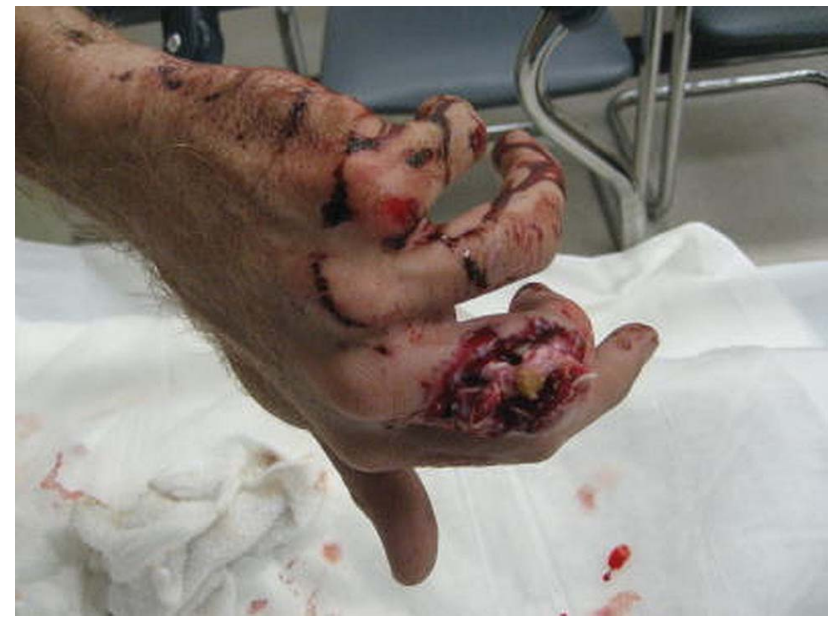

Figure 2 Serious hand lesions caused by contact with the engine prop; these injuries are specific to powered paragliding.

water; it is essential that pilots wishing to do so use selfinflating and specially designed safety systems. These auto-inflating flotation devices are mounted on the paramotor's frame and are activated by a $\mathrm{CO}_{2}$ cartridge, which fires on submersion, so no pilot input is required.

Paragliding injuries mainly involve lower limbs and spine, ${ }^{3}$ 9-17 whereas, in PPG, the upper limbs are more commonly affected and spinal injuries are less common. The different injury distribution may depend in part on the different flight dynamics and different distribution of the forces acting on the crew. This is due to the thrust of the engine and the weight of the equipment.

The engine is undoubtedly the factor that distinguishes PPG from paragliding in terms of injury type; contact with the propeller caused 43 accidents (11.22\%) in our study and was responsible for the majority of injuries to the upper limbs, in particular lesions to the hands (figure 2), wrists, forearms, arms and shoulders, as well as all 11 fractures with loss of fingers cited in this study. Contact with very hot engine parts was the cause of four cases of burns to the face, neck, back, shoulder, arm, elbow, forearm, calf, thigh and ankle, while two cases of generalised burns were the result of actual fires caused by combustion of the engine fuel. In another case, electrical burns to the chest and one arm were sustained following collision with high-voltage power lines. Contact with power lines is an established cause of accidents in paragliding too, while burns resulting from engine fuel combustion or contact with the engine are specific to PPG.

Indeed, PPG is widely believed to be safer than paragliding, and fatal events are considered to be rarer than in paragliding. ${ }^{1}$ In our study, $6 \%$ of accidents were fatal (fatal accidents/total number of accidents: 23/383).

This figure is no lower than the values cited in the literature for paragliding and hang-gliding (table 7), but is, however, comparable with the $6.1 \%$ of fatal paragliding accidents reported by Schulze $e t a l^{18}$ in a study very similar to ours, which was conducted using the data from incident reports.

Considering the differences between PPG and paragliding, further research on this sport and related injuries should be conducted separately from paragliding, in separate studies.

The results of this study suggest that further investigation should consider if the use of certain types of safety clothing and equipment would significantly reduce various risks specific to this sport. The effectiveness of protective gloves to protect against hand injuries, caused by contact with the spinning prop, should be evaluated in future studies.

As many prop strike injuries occur higher up the upper limb, where gloves would not be effective, an even better solution may be to add a so-called 'safety ring' to the engine cage. The safety ring is an aluminium ring that is mounted just forward of the radial arms and has the same radius as the prop. It is designed to make it difficult for an open human hand to reach the prop when it is in full thrust, and it adds very little in terms of expense and weight to the equipment. Further studies should evaluate its effectiveness, and its use could eventually be made obligatory, given that these injuries are often severe, in some cases involving amputation of the fingers.

Given the extreme danger caused by water immersion, it might be useful if pilots provided themselves with an auto-inflating flotation device when flying near water. As in paragliding, periodical checking and maintenance of equipment (the wing and lines in particular) are essential. In addition, in PPG, careful inspection and maintenance of the engine is vital, given that its malfunctioning could be a cause of major injury.

This study has some limitations. First, as there is no way of finding out exactly how many people knew about

Table 7 Studies on paragliding and hang-gliding reporting fatal outcome after accidents

\begin{tabular}{|c|c|c|c|c|}
\hline Sport & Study & Fatalities & Participants & Percentage of fatal events \\
\hline Paragliding & Krüger-Franke et al ${ }^{11}$ & 2 & 218 & 0.91 \\
\hline Paragliding & Schulze et $\left.a\right|^{18}$ & 25 & 409 & 6.10 \\
\hline Paragliding & Lautenschlager et al ${ }^{19}$ & 1 & 86 & 1.16 \\
\hline Paragliding & Fasching et $a l^{12}$ & 0 & 70 & 0.00 \\
\hline Hang-gliding & Foray et $a P^{0}$ & 7 & 200 & 3.50 \\
\hline
\end{tabular}


the existence of the database, the effect of underreporting bias, due to the voluntary nature of our data submission, cannot really be estimated. In addition, as the injury reporting form is online, only PPG pilots with access to the internet were able to participate. For this reason, even though most people use the internet, selection bias cannot be excluded.

Finally, the lack of a specific question about the kind of injury sustained on the form might have led to the loss of some data even though in almost all cases it was possible to obtain detailed information on the type of injury by carefully reading the narrative section of the reports. Data analysis was performed only by one researcher with no cross-checking.

\section{CONCLUSIONS}

This study reveals a pattern of accidents in PPG that is clearly different from that observed in paragliding: PPG accidents are more common during takeoff; weather and wind conditions have less influence in causing accidents; the energy from the engine and the weight of the equipment may aggravate accidents.

The pattern of injuries sustained in this sport is characteristic: they mostly involve the upper limbs, while those to the spine are less common. Finally, contrary to the common belief of experts in this sport, ${ }^{1}$ the number of fatal accidents/number of accidents is not lower than those that occur in paragliding and hang-gliding ${ }^{11} 12$ 18-20 (table 7). For these reasons, PPG should be analysed separately from paragliding in separate studies.

Further research will be useful to confirm the data of this study, to investigate the role of safety equipment such as protective gloves, safety ring and auto-inflating flotation devices, and to evaluate the effectiveness of periodical checks of the engine, to reduce certain risks specific to this sport.

Contributors The study was conceived by FF and JG. JG collected data. FF carried out statistical analysis and wrote the draft of the manuscript. All authors contributed to critical revisions of the manuscript and approved the final version.

Funding This research received no specific grant from any funding agency in the public, commercial or not-for-profit sectors.

Competing interests None.

Provenance and peer review Not commissioned; externally peer reviewed.

Data sharing statement No additional data are available.
Open Access This is an Open Access article distributed in accordance with the Creative Commons Attribution Non Commercial (CC BY-NC 4.0) license, which permits others to distribute, remix, adapt, build upon this work noncommercially, and license their derivative works on different terms, provided the original work is properly cited and the use is non-commercial. See: http:// creativecommons.org/licenses/by-nc/4.0/

\section{REFERENCES}

1. Footflyer-The source for powered paragliding information. http:// www.footflyer.com/Safety/Incidents/incidents_and_analysis.htm (Oct 2013).

2. Feletti F. Multiple injuries in paramotoring: a case report to assess this sport's risks. Am J Sports Sci 2013;1:7-11.

3. Rekand T. The epidemiology of injury in hang-gliding and paragliding. Med Sport Sci 2012;58:44-56.

4. USPPA- United States Powered Paragliding Association. http://www. usppamembers.org (Oct 2013)

5. Fuller CW, Ekstrand J, Junge A, et al. Consensus statement on injury definitions and data collection procedures in studies of football (soccer) injuries. Clin J Sport Med 2006;16:83-92.

6. Fuller CW, Ekstrand J, Junge A, et al. Consensus statement on injury definitions and data collection procedures in studies of football (soccer) injuries. Scand J Med Sci Sports 2006;16:83-92.

7. Fuller CW, Ekstrand J, Junge A, et al. Consensus statement on injury definitions and data collection procedures in studies of football (soccer) injuries. Clin J Sport Med 2006;40:193-201.

8. Lackner CK, Schlechtriemen T, Burghofer K, et al. The Munich NACA score: modification of the NACA score for preclinical emergency medicine. Notfall und Rettungsmedizin 2005;8:109-11.

9. Zeller T, Billing A, Lob G. Injuries in paragliding. Int Orthop 1992;16:255-9.

10. Schneider S, Abein V, Askew CD, et al. Changes in cerebral oxygenation during parabolic flight. Eur J Appl Physiol 2013;113:1617-23.

11. Krüger-Franke $\mathrm{M}$, Siebert $\mathrm{CH}$, Pförringer W. Paragliding injuries. $\mathrm{Br} J$ Sports Med 1991;25:98-101.

12. Fasching G, Schippinger G, Pretscher R. Paragliding accidents in remote areas. Wilderness Environ Med 1997;8:129-33.

13. Rekand T, Schaanning EE, Varga V, et al. Spinal cord injuries among paragliders in Norway. Spinal Cord 2008;46:412-16.

14. Hasler RM, Hüttner HE, Keel MJ, et al. Spinal and pelvic injuries in airborne sports: a retrospective analysis from a major Swiss trauma centre. Injury 2012;43:440-5.

15. Exadaktylos AK, Sclabas G, Eggli S, et al. Paragliding accidents-the spine is at risk. A study from a Swiss Trauma Centre. Eur J Emerg Med 2003;10:27-9.

16. Gauler R, Moulin P, Koch HG, et al. Paragliding accidents with spinal cord injury: 10 years' experience at a single institution. Spine 2006;31:1125-30.

17. Laver L, Mei-Dan O. Paragliding. In: Mei-Dan O, Carmont RM, eds Adventure and Extreme Sports Injuries. London: Springer-Verlag, 2013:247-72.

18. Schulze W, Richter J, Schulze B, et al. Injury prophylaxis in paragliding. Br J Sports Med 2002;36:365-9.

19. Lautenschlager S, Karli U, Matter P. Paragliding accidents: a prospective analysis in Swiss mountain regions. $Z$ unfallchir Versicherungsmed 1993;1:55-6.

20. Foray J, Abrassart S, Femmy $\mathrm{T}$, et al. Hang-gliding accidents in high mountains. A propos of 200 cases. Chirurgie 1991;117:613-17. 